\title{
CRISTEMAN, O TERRÍVEL: UM FAIT DIVERS DO SÉCULO XVI
}

CRISTEMAN THE TERRIBLE:

a 16th Century Fait-DIVERS

Rafael Marcelo Viegas

Universidade Federal do Rio de Janeiro Rio de Janeiro, RJ, Brasil

Palavras-chave: Fait-divers; Crime; Pasquim; Jornal.

Keywords: Fait-divers; Crime; Pasquim; Press.

Mots-clés: Fait-divers; Crime; Canard; Presse.

\section{Resumo}

A partir da primeira metade do século XVI, uma série de documentos de caráter pretensamente jornalístico começou a circular na França. Esses documentos, impressos em suportes semelhantes aos nossos livretos de cordel (papel barato, impressão de baixa qualidade), vendidos por ambulantes, traziam informaçôes sobre cataclismos, eventos prodigiosos e sobrenaturais, mas também mortes, crimes e assassinatos, verdadeiros faits divers - do qual a tradução a seguir constitui um breve exemplo.
Abstract

From the first half of the sixteenth century, a series of "journalistic documents" began circulating in France. These documents, printed in booklets similar to Brazilian cordel (cheap paper, poor print quality), sold by peddlers, with news about cataclysms, miraculous and supernatural events, but also deaths, crimes and murders, that is, faits-divers - which the translation below is a brief example.

\section{Resumé}

Dès la première moitié du XVIe siècle, une série de documents “journalistiques" a commencé à circuler en France. Ces documents, imprimés dans des fascicules similaires au cordel brésilien (papier pas cher, mauvaise qualité d'impression), vendus par des colporteurs, diffusaient des nouvelles sur des cataclysmes, des événements miraculeux et surnaturels, mais aussi sur les décès, les crimes et les meurtres contemporains, des vrais faits divers - dont la traduction ci-dessous est un bref exemple.
O material traduzido e comentado abaixo faz parte de um universo particular de narrativas do final do Renascimento francês, narrativas que mostram um quotidiano saturado de acontecimentos espetaculares, açóes demoníacas, catástrofes, crimes, assassinatos. Uma linhagem de impressos anteriores ao florescimento dos jornais, porém com diversas características semelhantes. Decorrência 
direta da prensa de tipos móveis de Gutenberg, gravadas em pequenos folhetos similares, no suporte, aos nossos livretos de cordel, essas narrativas circulavam na bagagem de ambulantes e camelôs, e eram lidas, virtualmente, por todas as camadas da população. A crítica moderna chamou esses suportes de canards ("pasquins") de faits divers - utilização anacrônica de termos emprestados ao circuito jornalístico do século XIX, mas que serve, em linhas gerais, para unificá-los e estruturar-lhes uma tópica comum: uma atividade intelectual de base sensacionalista, ou quase; uma relação ambígua com o "fato" jornalístico (que deve muito à dinâmica dos rumores); uma ergonomia informativa de tipo imanente e/ou pontual.

Minha proposta aqui é introduzir o leitor brasileiro nesse universo. $\mathrm{O}$ trabalho, na verdade, está inserido numa pesquisa mais ampla, envolvendo não apenas o fait divers renascentista, como também a novela, o trágico (em prosa) e a dinâmica de circulação dos rumores na França dos séculos XVI e XVII.

$\mathrm{Na}$ primeira parte deste artigo, ofereço uma breve história, advinda de uma fonte (francesa mas de um caso supostamente alemão) do final do século XVI: Cristeman Gempertingua de Corpen, possivelmente o maior assassino serial de todos os tempos. Seu modus operandi, seu desprezo pelos sentimentos humanos mais elementares, seus butins e seu fim.

Antes de passarmos à análise do relato, no entanto, será necessário constituir um contexto. Essa preliminar é importante, pois muito pouca coisa tem sido escrita a respeito do fait divers renascentista - os estudos clássicos, esgotadíssimos e sem referência em nossas bibliotecas, datam já de mais de meio século atrás. Assim, a introdução geral, que constitui a segunda parte deste trabalho, servirá, portanto, também de propedêutica para outras traduçóes desse repertório, que pretendo publicar mais adiante. $\mathrm{Na}$ terceira parte, faço algumas consideraçôes específicas relativas ao material traduzido logo abaixo.

\section{Discurso admirável sobre os crimes e os assassinatos} mais uma vez cometidos por um tal Cristeman, alemão condenado à morte na cidade de Berckessel, perto de Mayence, na Alemanha, que em seu processo confessou, entre outros crimes, ter matado e assassinado novecentas e sessenta e quatro pessoas ${ }^{1}$

Assim como a doçura e a amizade são coisas recomendáveis entre os humanos, pela mesma razão a crueldade e o homicídio

\footnotetext{
${ }^{1}$ Discovrs admirable des mevrdres et assasinatz de novveau commis par un nommé
} 
lhes são proibidos pelas escrituras santas e humanas: nos mandamentos do Decálogo, no amarás teu próximo como a ti mesmo; e no de não matar nem assassinar ninguém. Esses mandamentos são gerais e especiais. E, por meio de sua guarda e observaçáo, Deus estabeleceu sua Justiça - embora possa ser por algum tempo obliterada, é através dela que todo malefício é enfim conhecido, revelado e punido. Donde os numerosos exemplos, tanto no Velho quanto no Novo Testamento, e nas histórias profanas. Pois [Caim] sendo o primeiro do mundo a matar seu irmão, Abel, ainda que tivesse cometido o homicídio sem testemunhas, Deus justo quis que ele e sua posteridade fossem miseravelmente punidos e perecidos no dilúvio. Joabe, condestável do rei Davi, tendo morto por traição Amasa e Abner, embora no tempo do rei seu mestre tais assassinatos tenham sido dissimulados, o rei Salomão, após o falecimento de seu pai, o puniu. Em nosso tempo, encontram-se diversos homicidas e assassinos que reinaram em seus malfeitos por mais de dez ou doze anos. Mas não se encontra, por mais que fossem iguais em intenção de cometer o mal, nenhum semelhante em crueldade ao dito Cristeman.

Crueldades de malfeitores existem em vários livros e tratados, como a do italiano morando em Anvers, que, tendo uma discussão com um amigo seu conterrâneo, dissimulou o ódio que tinha contra ele durante quatorze anos, ao fim dos quais, simulando ser seu servidor e amigo, convidou-o para jantar - no que o amigo, acreditando que o tempo tinha feito esquecer suas inimizades particulares, concordou -, e pondo-o em uma cadeira falsa feita para esse fim, matou aquele que tinha convidado à mesa como amigo.

O assassino, por muito tempo incógnito, finalmente foi revelado e condenado a ser queimado na dita cadeira na cidade de Anvers.

Cristeman Alemand, execute à morte en la ville de Berckessel, pres de Mayence en Allemagne, lequel par son proces à confesse auoir entre autres crimes tué \& assassine neuf cens soixante \& quatre personnes. Iouxte la copie, Imprimee à Mayence. M.D.LXXXII. Este fait divers, impresso em 8 páginas e em formato in- $8^{\circ}$, encontra-se no catálogo da BNF sob a cota MP 3287. Reproduzido, com grafia modernizada, em LEVER, Maurice. Canards sanglants, Paris: Fayard, 1993: 7178. A língua é o moyen-français, com uma pontuação frequentemente confusa e uma sintaxe bastante truncada. $\mathrm{O}$ texto original foi estruturado em apenas quatro grandes parágrafos - reorganizados aqui para facilitar a leitura. No repertório Seguin, este fait divers é o de $\mathrm{n}^{\circ} 33$. 
Muitos assassinos foram executados por esta razão - após terem reinado por algum tempo em seus malefícios, finalmente caíram na armadilha preparada por eles contra outrem. Tal como acontecerá aos conspiradores e envenenadores que recentemente quiseram envenenar o senhor duque de Brabante e de Anjou, único irmão do rei, e matar e assassinar outros príncipes contra todo direito, humano e divino. ${ }^{2}$ Mas Deus, que conhece todas as açôes, não quis permitir que coisas tâo prodigiosas fossem cometidas por esses assassinos, executados ou não executados. As Escrituras entretanto, tanto do Velho Testamento quanto as histórias profanas lhe fazem fé, aquelas que por uma questão de brevidade permanecem por discorrer, imaginaram as crueldades de todos os ladrôes que foram executados por conta de seu mal feito. [Mas] Neste [nosso caso], o superlativo da maldade os superou; sua confissão o demonstra, seus atos o condenam, e finalmente não se pode dizer que o dito Cristeman não tenha sido o mais célebre, sutil e cruel malfeitor que se possa pensar, não tendo poupado ninguém, nem mesmo seus próprios filhos.

O que foi dito acima por prefácio e advertência, é que nenhum pecado permanece impune seja qual for o tempo que corra. Pois como diz o poeta, temporibus peccata latent, et tempore patent. não existe pecado oculto. ${ }^{3}$ Eis portanto o discurso sobre a vida e os costumes do dito Cristeman, e de seu julgamento. No vigésimo sétimo dia do mês de maio passado, foi preso e tomado prisioneiro em nossa vila de Berckessel, um bandido chamado Cristeman Gempertingua de Corpen (cidade a duas léguas de Colônia), ${ }^{4}$ que, pelo espaço de treze anos, viveu como ladrão e durante sete morou numa floresta chamada Frasberg, a uma légua de nossa cidade, onde estava tão bem instalado que não seria possível ser melhor. Tinha se posicionado num lugar a partir do qual descobria facilmente todos os que passavam sobre as grandes rotas em direção a Treves,

\footnotetext{
${ }^{2}$ Em agosto de 1582, descobriu-se uma conspiração para matar Francisco, duque de Anjou, quarto filho de Henrique II e de Catarina de Médicis, e irmão de Henrique III. Liderada por Balduíno e por Salcedo, o Jovem (filho de um espanhol morto no Massacre de São Bartolomeu), o episódio aparece no Journal de Pierre de L'Estoile, que data a morte do primeiro em agosto de 1582 e a execuçáo do segundo em 23 de outubro de 1582.

${ }^{3}$ Versos de Catão: Nolo putes prauos homines peccata lucrari:/ Tempore si peccata latent, et tempore parent. [Náo pense que os malvados vencerão / Ocultos por um momento, o tempo mostra seus pecados]. Disticha Catonis, II, 8.

${ }^{4}$ Atual Kerpen, 30 km a leste de Colônia.
} 
Metz, Diessenhofen e ao Ducado de Luxembourg - onde diversos comerciantes fazem negócios. Esse infeliz sendo feito prisioneiro, confessou ter, desde a juventude, cometido novecentos e sessenta e quatro homicídios.

Isso seria considerado incrível, se não se tivesse encontrado em seu poder um caderno com todos os que ele matou, escrito de próprio punho, com o dia e o modo como tudo aconteceu. Ora, seu abrigo era naturalmente bem construído e recheado de porões, gabinetes, células próprias para morada, e mobiliada com toda sorte de utensílios. Além disso, havia provisóes de vinho e de carnes frescas e salgadas para durar um ano. Assim como armas de todos os tipos e em grande número, como arcabuzes, espadas, morrióes, corseletes, que fariam sofrer os soldados que o prenderam - se ele não tivesse sido surpreendido dormindo. Aqueles que caíam em suas mãos, ele os punha a morrer sem remissão, depois os jogava num poço profundo, que ele tinha encontrado nos arredores, preparado para tal. Quanto aos despojos, como roupas, dinheiro, armas e bagagens, ele levava tudo até a caverna, na qual se encontrou também todo tipo de mercadoria, roubadas de alemães e de outros, em tal quantidade que poderiam abastecer uma feira e que muitos estimaram chegar a valer mais que de setenta mil florins de ouro da Alemanha. Confessou também que sua meta era matar até chegar ao número de mil pessoas, depois se dar um bom tempo sem matar nem roubar ninguém.

Mas bem quis Deus Todo-Poderoso, descobrindo esse assassino execrável pela boca de uma mulher que ele manteve sete anos inteiros em sua caverna. Essa mulher era de uma cidade chamada Popert sobre o Reno, e filha de um barriqueiro. Estando um dia na estrada para visitar seus irmãos, o malvado a atacou para matá-la. Mas [foi] vencido por sua beleza: "É preciso", diz ele, "que tu me faças companhia, senão te matarei como fiz aos outros". Ela, temendo a morte, concordou com o que ele quis e prometeu náo acusá-lo nem traí-lo. Então, ele a levou para sua caverna, e durante os sete anos que ela aí ficou, teve seis filhos, que ele degolava assim que nasciam e os punha num lugar alto, e depois os pendurava pelos pés a fim de curti-los. E assim que o vento soprava de um lado a outro nessas pequenas criaturas, o cruel endemoniado dizia: "Dancem, dancem, meus queridos filhos! Pois Gempertingua, seu pai, dá o tom da dança”. Era um espantoso suplício feito a esta pobre mulher, e para piorar sua infelicidade ele a acorrentava, por medo 
que fugisse, enquanto ele e seus companheiros saíam da caverna para roubar e matar os passantes. Após tê-los saqueados, querendo que tudo lhe pertencesse, levava seus companheiros para a caverna, onde misturava na bebida e na comida certo veneno táo violento que eles morriam cinco ou seis horas depois.

Ora, o Senhor Deus, querendo fazer justiça, quis que esta mulher, que se arrependia continuamente dos pecados que cometera, e que invocava sua ajuda, obteve um dia autorização do assassino para ir uma vez visitar seus pais. Ela foi, mas, sem nada revelar na ocasião, voltou à caverna. [Deus] lhe deu vontade de lá retornar uma segunda vez, e fez de maneira que aquele o permitiu - fazendo, porém, que ela lhe prometesse, antes de partir, e com grandes recomendaçôes, não o trair. Ora, esta pobre mulher, entrando em nossa cidade de Berckessel, vendo as crianças que brincavam nas ruas, começou a sentir sua consciência, e tomada de emoção, se pôs a chorar e a se desmanchar em lágrimas, dizendo: "Ó Deus que mantém todas as coisas, a quem meus pecados não podem ser ocultos e que conhece o juramento que fiz sob coerção, eu imploro olhar com piedade para minhas angústias, que suportei em minha carne e em meu próprio sangue". Ela se lamentava e suspirava táo alto que as pessoas se acercaram dela para saber a causa de tal infortúnio. Mas não se lhe podia tirar nada senão uma infinidade de lágrimas. $\mathrm{O}$ que levou alguns a advertir a Justiça, diante da qual ela foi levada - mas, inquirida pelos magistrados, nada quis confessar, dizendo ter feito juramento de nada dizer a ninguém. Então, pressionaramna e rogaram, em nome de Deus, para esvaziar seu coração, e que seria liberta de seu juramento, se o conhecimento de tal coisa não ocasionasse a ruína de sua alma. Com isso, como recobrasse novos ânimos, ela fez um amplo discurso do ocorrido acima, para grande espanto de todos os oficiais de Justiça - que, tendo decidido sobre o que era necessário, instruíram a mulher a respeito do que fazer.

Ela retomou seu caminho até a caverna, carregando um saco cheio de ervilhas, ${ }^{5}$ que derramava pelo chão até chegar ao local, a fim de que trinta soldados bem armados pudessem sem problema achar a caverna, onde viram o bandido adormecido no colo da mulher. Pois ela o tinha entretido com belas frases, e fingindo procurar piolhos, o fez adormecer, de tal modo que ele se viu preso e enlaçado ao acordar. "Ó puta desleal", gritou, "se eu tivesse imagi-

\footnotetext{
${ }^{5}$ Literalmente "poix" [piche] no texto original. Lever transliterou como "pois", o que neste caso teria de ser traduzido como "ervilhas" - transliteração que sigo aqui.
} 
nado isso, já teria te estrangulado há muito tempo". Se não tivesse sido preso dormindo, teria dado trabalho aos trinta soldados, sendo homem robusto, muito bem armado e bem resguardado. Mas foi rapidamente amarrado e levado a Berckessel, onde, torturado, confessou, sem se fazer apressar, as maldades sobrescritas, ajuntando que estava resolvido a matar até o número de mil pessoas, e depois se aposentar.

Ele foi condenado a ter os braços e as pernas arrancados, depois ser posto na [no suplício da] roda para aí definhar, onde sobreviveu nove dias inteiros, durante os quais lhe forneceram carne e bebida para prolongar mais o suplício, [embora] ele tivesse merecido [um] ainda mais horrível, sem comparação. Todos os bens encontrados na caverna foram levados à cidade e postos em lugar reservado, sem que se haja ainda resolvido o que se deverá fazer deles. Estima-se que tal punição servirá de exemplo a outros.

Por este motivo, juízes que julgam a terra, reconheçam e façam com que a justiça seja observada e guardada, os ladróes prontamente punidos e castigados, a fim de que sob o Século dourado, livremente em toda certeza, possamos amigavelmente comerciar juntos - homicidas e assassinos punidos.

FIM 
Pouco antes do aparecimento dos primitivos jornais (estruturas montadas para a transmissáo impressa e periódica de notícias, com corpo relativamente organizado e recorrente de articulistas e colaboradores), ${ }^{6}$ o cenário do circuito noticioso europeu foi invadido por uma grande massa de textos, de caráter pontual, tratando de eventos particulares. Esses textos são parte de um conjunto-universo novo, o dos hoje denominados boletins de informação, ou ocasionais. ${ }^{7}$

Embora não fossem os únicos veículos de comunicação no período imediatamente anterior ao aparecimento dos jornais (os mensageiros, os viajantes, soldados em campanha, os éditos e diversos outros dispositivos escritos e orais, como os rumores, cumpriam esta tarefa), ${ }^{8}$ a difusão de notícias teve, nos boletins publicados pontualmente - isto é, cada vez que um fato importante ou sensacional vinha à luz, daí o nome de "ocasional" -, um dos seus principais meios propagadores. ${ }^{9} \mathrm{Na}$ França, e alhures, eles foram um medium importante de circulação de notícias para o grande público já no século XV: incluindo-se aí desde o iletrado - que ouvia os

${ }^{6} \mathrm{Na}$ França, a imprensa periódica só aparecerá em 1631, com a publicação do primeiro número do semanário La Gazette, impresso por Théophraste Renaudot. Minha definição do jornal do século XVII não difere muito daquela do jornal tal como a conhecemos hoje - exceto, talvez, neste caso, pelo papel dado à publicidade -, mas, como se trata apenas de uma definição contextual, não entrarei no mérito de sua especificidade.

${ }^{7}$ Uma arqueologia exaustiva da pré-história dos jornais deveria retroagir até contemplar uma análise dos Acta diurna do Império Romano - publicações diárias [diurna] que circulavam trazendo todo tipo de informação (de casamentos a crônicas esportivas e teatrais), redigidas pelos diurnarii [diaristas] (ancestrais dos jornalistas modernos). Salústio, por sua vez, um dos protegidos de Júlio César, era o redator de uma publicaçáo periódica, o Commentarius Rerum Novarum [Crônica das novidades], semanário que empregava 300 escravos escribas com $10 \mathrm{mil}$ exemplares por edição (Cf. Wolgensinger, Jacques. L'Histoire à la Une. La grande aventure de la Presse, Paris: Gallimard, 1989: 14-15). Não sendo o objetivo último deste artigo fazer uma história da imprensa, mas a contextualização do noticiário no final do Renascimento, me desincumbo desta tarefa historiográfica geral. 8 "De façon générale, le rôle fondamental que joue la rumeur dans l'espace public reste à découvrir, alors qu'elle agit à la fois comme information et comme contestation de l'information dans les milieux populaires." (Billoré, Maïté; Soria, Myriam. La Rumeur au Moyen Age. Rennes: Presses Universitaires de Rennes, 2011: 27). 9 Lembro que essas denominaçôes ("ocasional", "boletim de informação", "fait divers”) são retroativamente anacrônicas em relação ao período considerado aqui, final da Idade Média e Renascimento, uma vez que se trata de uma nomenclatura jornalística que vem do século XIX. 
relatos lidos em voz alta pelos alfabetizados - até o cronista e o historiador seus contemporâneos, que utilizavam esses boletins como fontes diretas ou indiretas..$^{10}$

Trechos de cartas, relatórios, testemunhos em primeira mão (de atores ou observadores diretos, de coadjuvantes), mas também testemunhos indiretos, (retomados de outras fontes, mais ou menos confiáveis), ou simplesmente informações falsas ou de teor falacioso, esses textos, por conta de diversas circunstâncias, foram publicados com crescente interesse pelos florescentes e ativos impressores do Renascimento. ${ }^{11}$

Normalmente de pequenas dimensóes - com poucas folhas e papel ruim, muitas vezes ilustrados, usando tipos já gastos e as sobras da confecção dos produtos editoriais de primeira linha (livros), numerosas imprecisóes ortográficas (uma mesma palavra

${ }^{10}$ Essa nova dinâmica da informação não é, claro, específica à França. Em algumas regiôes, como na Itália, na Alemanha e nos Países Baixos, a produção de boletins e ocasionais reunia uma verdadeira estrutura de notícias - à qual faltava somente periodicidade para ser considerada como jornalística. No caso desses países, os ocasionais operavam com conteúdos de interesse direto para o comércio: "Quant aux nouvellistes [i.e., os profissionais de notícias] vivant de leur profession, ils devinrent très nombreux. Certains avaient de véritables bureaux bien organisés: Jérémie Krasser dirigea un bureau de ce genre à Augsbourg, qui fut repris après sa mort pour Schiffle; tous les deux travaillaient pour les Fugger et pour d'autres clients. Les électeurs de Saxe payaient de nombreux correspondants (parmi lesquels figure Hubert Languet) pour leur envoyer les feuilles dont la collection est conservée aujourd'hui à Dresde. Certains nouvellistes cherchèrent à étendre leur clientèle. Un témoin du XVIe siècle voit à Hambourg un bureau de ce genre, où les diplomates et bien d'autres personnes viennent se procurer des nouvelles manuscrites et imprimées. C'est en Italie surtout que le commerce des fogli a mano se vulgarise. A Venise on les vendit publiquement sur le Rialto dans une boutique; nombreux étaient dans cette ville les professionnels, appelés tour à tour menanti, novellanti, rapportisti, gazettanti. Ce dernier terme nous rappelle que, d'après la tradition, le mot "gazette» vient de la petite pièce de monnaie vénitienne (gazzetta) qui payait la feuille mise en vente (...)" (WEILL, Georges. Le Journal. Origines, évolution et rôle de la presse périodique, Paris: Renaissance du livre, 1934: 11-12).

${ }^{11} \mathrm{Na}$ França, a voga começou com as Guerras da Itália: "Sous Charles VIII, de nombreuses pièces de cette nature avaient fait connaître, parfois presque jour après jour, à un public assoiffé de nouvelles, les péripéties des campagnes d'Italie. D'autres reproduisaient les textes de traités importants ou relataient les circonstances d'entrées de souverains; d'autres, enfin, vulgarisaient le texte de la lettre de Christophe Colomb ou racontaient de passionnants faits divers. Au début du XVIe siècle, les bulletins d'information se font de plus en plus nombreux, et leur clientèle s'accroît. Les règles du genre, dans le choix de nouvelles et dans leur présentation, sélaborent telles quion les retrouvera pratiquées par les éditeurs de gazettes, par les canardiers et par les journalistes à venir." (SEGUIN, Jean-Pierre. L'Information en France de Louis XII a Henri II. Genève: Droz, 1961: 7). 
escrita de maneiras diferentes na mesma página, por exemplo) -, esse material, feito visivelmente para consumo rápido e amplo, é hoje, por conta desses fatores de produção (e pelo fato, não menos importante, de não terem sido absorvidos pelas bibliotecas da época), considerado raro. ${ }^{12}$

A folha impressa dos ocasionais não substituiu a circulação de manuscritos dos cronistas (anônimos ou não), que continuaram copiados e recopiados no mesmo sistema, mas algumas particularidades foram sendo sentidas na dinâmica da informação em papel. Os boletins, que, de início, tal como no caso das crônicas e das memórias clássicas e medievais, se concentraram sobre acontecimentos bastante aristocráticos (entronizaçóes, casamentos reais, grandes batalhas, golpes de estado), ${ }^{13}$ vão, aos poucos, oferecendo um quadro mais amplo, levando ao seu público também notícias sobre a atualidade geral - quer dizer, notícias cujo fundo e interesse não era necessariamente aristocrático. Essa mudança de conteúdo dos ocasionais políticos e históricos do século XV para os do século XVI, de espectro mais largo, é de fundamental importância para todo o circuito de narrativas produzidas no século XVI - e não somente no que diz respeito às gazetas e periódicos posteriores. E tal como no caso do livro, mas ampliado aqui por conta das vicissitudes do formato, a facilidade de imprimir cópias a partir de uma matriz (inerente ao sistema de prensa de tipos móveis de Gutenberg) lhe forneceu, portanto, um meio de produção eficiente, massivo e relativamente barato. ${ }^{14}$

\footnotetext{
${ }^{12} \mathrm{O}$ acervo da Bibliothèque Nationale de France $[\mathrm{BNF}]$ possui a mais importante coleção de occasionnels em língua francesa, alguns deles já digitalizados e oferecidos na base Gallica. Os principais estudos de conjunto sobre essa coleção foram publicados a partir do final dos anos 1950, sendo os dois livros de Jean-Pierre Seguin, L'Information en France de Louis XII a Henri II (1961) e L'Information en France avant le périodique (1964), ainda fundamentais. Este último livro é a reunião corrigida de artigos publicados anteriormente na revista Arts et traditions populares. Fundamental para o estudo do canard, ele foi publicado como sequência de artigos em ATP T. XI no 1, Janvier-Mars 1963: 20-32; ATP T. XI no 2, Avril-Juin 1963: 119-145; e ATPT. XI no 3-4, Juillet-Décembre 1963: 203-280. 13 Exceção feita aos boletins do final do século XV, sobretudo na Itália e nos Países Baixos, que também traficavam informaçôes de caráter funcional para o comércio. ${ }^{14}$ Para os impressores do Renascimento, o valor econômico dos boletins de informação é, desde o início, bastante significativo, mas de modo pontual: "S'il existe déjà quelques spécialistes [em imprimir ocasionais] - P. le Carron et J. Lhomme surtout ont droit à ce titre - pour la plupart des autres imprimeurs, les bulletins d'information n'étaient qu'un moyen, plus ou moins souvent employé, de réaliser une bonne affaire en vendant rapidement, à une clientèle étendue, une marchandise pro-
} 
Efetivamente, a partir do começo da década de 1530, na continuidade desse mercado, os boletins franceses começaram a mostrar também um interesse sistemático pelo acontecimento puramente quotidiano, i.e., o acontecimento sem necessariamente uma implicação política, econômica ou religiosa clara ou ao menos declarada. Em outras palavras, por esta época, os editores também começaram a publicar aquilo que modernamente chamamos de fait divers. ${ }^{15}$

Essa mudança de atitude com relação aos "fatos" da "vida ordinária" é uma verdadeira revolução. De 1529 em diante, os faits divers entrarão no circuito do noticioso como uma força autônoma e decisiva, de apelo e consumo populares. Seu veículo de proliferação será o canard - definido, para todos os efeitos, embora tautologicamente, como o ocasional que compila um fait divers. ${ }^{16}$

duite à peu frais." (Seguin, Jean-Pierre. L'Information en France de Louis XII a Henri II, op. cit.: 50).

15 "Pour la période 1488 à 1529, J.-P. Seguin a retrouvé près de 200 occasionnels, mais aucun ne relate un fait divers, ce qui est assez curieux. A partir de cette date, les canards se multiplient. Le Journal d'un bourgeois de Paris [sous le règne de François I], de 1515 à 1536, en consigne d'innombrables. Pierre Boaistuau en rassemble dans un recueil sous le titre Histoires prodigieuses en 1560" (Bellanger, Claude et allii. Histoire générale de la presse française. 1, Des origines à 1814. Paris: PUF, 1969: 41). Aproprio-me, aqui, como se vê, de um conceito clássico de fait divers - tal como o usado, entre outros, por Roland Barthes (Barthes, Roland. "Structure du fait divers" [original 1962] in Barthes, Roland. Essais Critiques, Paris: Seuil, 1964: 188-197). Lembro novamente que, embora de uso corrente pelos especialistas (em particular por Seguin), o emprego do termo fait divers aqui é anacrônico: só começou a ser utilizado no circuito jornalístico no primeiro terço do século XIX (o Robert traz a data de 1838), designando uma rubrica noticiosa reunindo os acontecimentos menores do quotidiano - quer dizer, aqueles sem lugar nas grandes rubricas de um jornal (Política ou Economia, por exemplo). Importa dizer que, se exagero essa ideia de canard "sem implicações" e "fora das rubricas clássicas", é unicamente com fins didáticos - pois os canards estão cheios de implicaçôes ideológicas dos mais diversos níveis, destacáveis a partir de uma análise mais fina e específica que a proposta meramente introdutória que faço aqui. ${ }^{16}$ Preferi não traduzir canard por "pasquim", que seria o termo equivalente em português, por três motivos: 1). trato aqui de fontes francesas; 2 ). por ser o termo pasquim demasiadamente ligado entre nós a uma tradição de sátira e crítica política - o que não é necessariamente o caso no canard (veja-se a etimologia proposta por Houaiss, Dicionário da lingua portuguesa, entrada "pasquin-"); 3). e também porque canard (literalmente "pato") conserva em si, por sinédoque, uma referência ao aspecto oral (o grasnar agudo do pato) da circulação de notícias que não deve ser esquecido em nosso contexto. A obra essencial para a análise do $c a-$ nard francês da época aqui considerada é Seguin, Jean-Pierre. L'Information en France avant le périodique. 517 canards imprimés entre 1529 e 1631. Paris: G.-P. Maisonneuve et Larose, 1964). Algumas peças do repertório de 517 canards, boa parte dele inventariado a partir do acervo da Bibliothèque Nationale no final da 

Seguin:

(...) est un imprimé vendu à l'occasion d'un fait divers d'actualité, ou relatant une histoire présentée comme telle.

Ilpeut avoir des liens plus ou moins étroits et avoués avec les évènements politiques et religieux contemporains, mais le fait divers y demeure le principal motif d'intérêt et si propagande il y a, celle-ci passe sous son couvert.

Le canard peut être imprimé au recto seul d'une feuille de grand format illustrée, comportant assez de texte pour se différencier de l'image, mais il se présente presque toujours sous la forme d'une brochure d'un ou de deux, très rarement de trois cahiers, généralement composée à la hâte, sur un papier de médiocre qualité. *

O termo canard é empregado por Seguin numa dimensão conceitual e técnica, claro, mas ele já é popularmente corrente, no século XVI, para designar notícias impressas vendidas nas ruas.. Neste sentido, existiria uma clara continuidade entre o noticiário oral de atualidade e seu "homônimo" impresso, pois "canard" traduz bem, em última análise, o estado ordinário "oral” de circulação da informação: publicados às vezes em cadernos de até 25 páginas (embora normalmente oscilando em peças in $-8^{\circ}$ de 10 a 16 páginas), frequentemente com a folha de rosto ilustrada (ainda que as gravuras pouco tenham a ver com o conteúdo), ${ }^{17}$ canards e bulletins não eram comercializados em bancas, lojas ou casas de edição, mas por ambulantes (colporteurs e vendeurs à là criée) que gritavam o seu conteúdo nas ruas. ${ }^{18}$

década de 1950, foram perdidas - ao que parece, extraviaram-se no próprio acervo da BNF, segundo o que pude constatar em pesquisa local. Desde entáo, outros canards foram descobertos em bibliotecas menores e acervos diversos, mas o inventário de Seguin permanece referência obrigatória para o estudo desse material. O mais antigo canard francês de que se tem notícia se intitula Le grand Miracle Dung enfant ne Par la voulente de Dieu en la ville de Norden, au pays de Frise, en Allemagne (abril de 1529) e foi modernamente publicado no: Bulletin du bibliophile, mai-juin 1890: 201-208.

17 "C'est ainsi que la crue de la Seine en 1579 est illustrée par une vue de Venise en 1480", entre outros tantos exemplos. (Cf. Wolgensinger, Jacques. L'Histoire à la Une. La grande aventure de la Presse, op. cit.: 17).

${ }^{18}$ Colporteurs no campo e "vendeurs à la criée" (literalmente, "vendedores na base do grito") nas cidades, com seus cestos cheios de impressos pendurados em torno do pescoço (Cf. Wolgensinger, Jacques. L'Histoire à la Une. La grande aventure de la Presse, op. cit.: 17; duas ilustraçôes de gritadores em ação na p. 13 desse volume). Pierre de L'Estoile dá, em seu diário, uma ideia de como funcionava esse comércio: "Le jour mesme [2 de agosto de 1611] on crioit un Discours du marquis des Sorciers, fait par un nommé La Fontaine, médecin du Roy, sur les subject
* (SEGUIN, Jean-Pierre. L'Information en France avant le périodique, op. cit.: 8.) 
Concomitantemente, por funcionarem num registro, por assim dizer, sensacionalista, os bulletins e, sobretudo, os canards guardam, embora suportes impressos, algo da dinâmica dos rumores, da fofoca e, logo, da comunicaçáo oral.

De temática ampla, indo de catástrofes naturais a prodígios, de processos de bruxaria a assassinatos, o canard é evidentemente um veículo novo, que veio estabelecer um universo diferente, ainda que solidário, daquele dos boletins de informaçáo anteriores. Ele acompanha de perto a intensificação da informação impressa na Europa, mas com uma dinâmica que lhe é particular, sobretudo no aspecto espetacular. ${ }^{19}$ Muito embora nem sempre digno de crédito por seus contemporâneos intelectualizados, é visto com simpatia e interesse pelo público das cidades e dos campos - o que reproduz, avant la lettre e guardadas as proporçóes, muitas das questóes em torno da objetividade e da imparcialidade dos meios de informação dos jornais nossos contemporâneos. ${ }^{20}$

du procès fait au prestre de Marseille, sorcier, nommé Louis Gaufridi. M'a cousté deux sols." (L'Estoile, Pierre de. Mémoires-Journaux, Vol. XI. Paris: Alphonse Lemerre, 1906: 135). Evidentemente, não são apenas canards ou bulletins que são vendidos dessa maneira, tampouco a tradição da vente à là criée é especificidade dos ambulantes de notícias: os cris de Paris são uma verdadeira instituição, que existe até hoje, sendo catalogada por observadores e artistas de diversas épocas (uma célebre chanson polifônica renascentista de Clément Janequin, usando exclusivamente frases cantadas por comerciantes de rua e de feiras parisienses, se intitula justamente Les Cris de Paris; existe gravação em CD feita por Dominique Visse com o Ensemble Clément Janequin). A figura do crieur público, por sua vez, o portador de notícias oficiais do governo ou de instituiçóes públicas ou privadas, embora vista com frequência em diversos filmes retratando a Idade Média, é ainda relativamente pouco estudada. Para uma análise recente do papel desse tipo de funcionário, ver Offenstadt, Nicolas. En place publique: Jean de Gascogne, crieur du XVe siècle. Paris: Stock, 2013.

${ }^{19}$ Jean-Pierre Seguin tenta isolar o conteúdo e as estratégias do canard em relação ao boletim de informação: “(...) emporté par son sujet et désireux d'en accentuer le côté sensationnel, le narrateur empiète un peu dans le domaine de la fiction. Un de ses congénères y glisse franchement, dans un autre texte relatant l'apparition d'un dragon dans le ciel de Paris. Cette fois, comme toujours en pareil cas, les éléments empruntés au réel ont pour but de faire passer un fait imaginaire, que le lecteur aura plaisir à croire vrai." (SEGUIN, Jean-Pierre. L'Information en France de Louis XII a Henri II. op. cit.: 41). Mais adiante, diz que o interesse documentário no boletim de faits divers "n'est pas exactement de même nature que celui des autres bulletins, ni tout à fait semblable la manière de leurs auteurs". (Ibidem: idem).

${ }^{20}$ Através de Pierre de L'Estoile, "nous savons que la masse, émotive et passionnée, prenait souvent pour argent comptant toute fable imprimée. Nous connaissons aussi les réactions des esprits cultivés et critiques dont il est le représentant: la liste est longue des termes péjoratifs quil emploie pour qualifier les occasionnels en général et ceux de faits divers en particulier: «balivernes, fadèzes, fables, bagatelles, baguenaudes, trique- 
Trata-se, efetivamente, de um fenômeno midiático: se, entre 1529 e 1550, temos apenas 18 títulos de canards sobreviventes (descontadas as eventuais cópias do mesmo título), passamos a 39 entradas entre 1550 e 1575; a 110 entradas entre 1575 e 1600; e a 323 entradas entre 1600 e 1631 . $^{*}$ Nesse caso, considerando apenas os exemplares que chegaram até nós, temos no mínimo um título de canard por mês nos primeiros trinta anos do século XVII. Evidentemente, o aumento do número bruto dos canards também se deve à proliferaçáo de editores capaz de imprimi-los (estamos no primeiro grande boom editorial da Europa moderna após a invenção de Gutenberg), mas, dadas as condições materiais precárias e inerentes a esse tipo de suporte (tornando impossível saber ao certo quantas peças foram de fato impressas nos períodos citados), o aumento proporcional entre os decênios mostra que, ao final de Renascimento, o canard é um claro sucesso de público. Muito embora popular, por volta da última metade do século XVI, ainda não existem editores totalmente especializados em sua produção, mesmo em Paris (o maior centro consumidor e produtor). Lucro quase certo, o canard permanece, portanto - enquanto produto na linha de montagem editorial -, secundário e de circunstância. ${ }^{21}$ Entre as razóes de seu sucesso, certamente está o preço: canards são

niques, drolleries, amusebadaus, sornettes, charlatanneries, folastreries, fables», etc." (Seguin, Jean-Pierre. L'Information en France avant le périodique op. cit.: 23). A nomenclatura usada por L'Estoile não é, evidentemente, precisa. Fadèze, sornettes, fables, charlatanneries (termos negativos e derrisórios) não são empregados em seu diário apenas no contexto de documentos impressos, mas servem também, como adjetivos e substantivos, a uma ampla gama de circunstâncias - normalmente de cunho fraudulento. O contexto geral é o da tromperie, noção importante no contexto dos fabliaux e da novela renascentista. No entanto, a partir do final de 1606, L'Estoile começa a preferir os termos fadèze e, sobretudo, bagatelles quando se refere particularmente aos canards.

21 "À Paris, les plus gros éditeurs de canards ne sont aucunement spécialisés dans la production de livres peu coûteux pour un public "populaire" mais, à l'occasion, font rouler leurs presses inoccupés pour imprimer ce matériel au prix de revient faible et à la large diffusion." (Chartier, Roger. "Stratégies éditoriales et lectures populaires, 1530-1660" in Martin, Henri-Jean; Chartier, Roger. Histoire de l'édition française. I, Le livre conquérant: Du Moyen Age au milieu du XVIIe siècle. Paris: Promodis-Ed. du Cercle de la librairie, 1983: 597). Em Lyon, por sua vez, o mercado de canards era dominado por um único impressor, Benoît Rigaud, "qui imprime près du quart des éditions faites dans la ville. Pour lui, la publication des occasionnels sinsère dans une activité centrée sur l'édition des livrets bon marché-ce qui ne veut pas dire destinés à un même public - : almanachs et prédictions, chansons et poésies, actes officiels" (Chartier, Roger. "Stratégies éditoriales et lectures populaires, 1530-1660", op. cit.: 597).
* (Cf. SEGUIN, Jean-Pierre. L'Information en France avant le périodique. op.cit.: 14) 
mídias baratas se comparadas aos livros - variando entre 1 e 5 sols franceses por peça. ${ }^{22}$ Seria difícil medir esses valores em termos de moedas de hoje, mas as diferenças de preço entre livros e canards é, proporcionalmente ao menos, bastante significativa.

Dos 517 títulos de canards repertoriados e estudados por Seguin, numa amostragem que vai de 1529 a 1631 (ou seja, um século de produção), 109 são relatos de crimes; 116 de calamidades diversas (enchentes, tempestades etc.); 95 de fenômenos celestes; e 180 descrevem eventos mais ou menos maravilhosos. ${ }^{23}$ Ao menos tematicamente, portanto, o sucesso do canard está ligado ao interesse popular pelo fait divers - o que pode parecer redundante, uma vez que a definiçấo de canard se confunde com a deste último. Mas esse interesse não é uma especialidade apenas do canard. $\mathrm{O}$ fait divers também ocupa um lugar importante na composição dos journaux (diários) que lhe são contemporâneos, como o Journal d'un bourgeois de Paris sous le règne de François I (autor anônimo, 15151536); e nos congêneres de Pierre Driart (Chronique parisienne, 1522-1535), de Nicolas Versoris (Livre de Raison, 1519-1530), de Claude Haton (Mémoires, 1553-1582), de Gilles de Gouberville

\footnotetext{
${ }^{22}$ No sistema monetário do Antigo Regime, 1 sol era subdividido em 12 deniers e, por sua vez, valia $1 / 20$ de uma livre tournois - sendo esta a proporçáo monetária de referência na França, de 1200 (quando a livre tournois substituiu a livre parisis) até o século XVII. Pierre de L'Estoile nos diz, em suas Mémoires, que, em setembro de 1608, pagou 48 sols pelos dois tomos das Fleurs des exemples de Antonie d'Avroult (coletânea de milagres e narrativas catequéticas ou edificantes); 20 sols pelo $5^{\circ}$ tomo da Historiarum sui temporum, de Jacques Auguste de Thou; 10 sols por um Édict et déclaration du Roy Henry Quatriesme de France, et 3 de Navarre... (203 páginas a propósito da incorporação patrimonial da coroa de Navarra pela coroa francesa), publicado por Pierre de Belloy; e 70 sols por uma ediçáo de cerca de 1.000 páginas do Discours des Spectres de Pierre Le Loyer. Todos os volumes com costura e capa de pergaminho. Por outro lado, em janeiro do mesmo ano, comprara duas novas "bagatelles" (Un Deffy du Grand Sophi de Perse au Grand Turq e o canard Histoire tragique de la constance d'une dame envers son serviteur...) pagando, por ambas as peças, a quantia de 2 sols. Mais tarde, em março de 1609, pagou 1 sol pelo canard Discours veritable de l'execrable cruauté commise par une femme nommée Marie Hubert...; e 3 sols pela Histoire prodigieuse de l'assassinat commis en la personne d'un jeune advocat... Em 23 de abril, comprou o canard Histoire nouvelle et prodigieuse d'une jeune fermme laquelle pendit son père... pela quantia de 1 sol.

${ }^{23}$ Essa divisão nem sempre fica clara na leitura dos textos, pois não quer dizer que temas diferentes não possam se interpenetrar num mesmo canard. Vale lembrar, também, que as entradas do repertório de Seguin incluem duplicatas e referências a outros suportes (como os diários), o que praticamente duplica o número total de seus faits divers.
} 
(Journal, 1549-1562), entre outros. ${ }^{24}$ No mais antigo, o Journal d'un bourgeois de Paris..., aparece, já em junho de 1515 (bem antes da voga dos faits divers), uma nota breve sobre um assassinato que poderia, perfeitamente, se enfeitado com mais retórica, figurar nas páginas de um canard. ${ }^{25} \mathrm{O}$ texto é ainda mais surpreendente porque é o único do gênero dentre as anotaçóes registradas pelo Bourgeois de Paris nesse mesmo ano - todas as outras são, sem exceção, exclusivamente aristocráticas, quer dizer, no regime temático dos occasionnels, não dos canards. Em outro exemplo, o relato de um enforcamento fracassado (ocorrido em 19 de setembro de 1528), com todas as tintas de um legítimo fait divers, ocupou as atençóes de Versoris, de Driart e, novamente, do Bourgeois de Paris. * Era algo que estava, pois, no ar do tempo.

\footnotetext{
* (Cf. ANÔNIMO. Journal d'un bourgeois de Paris sous le règne de François 1er (1515-1536). Paris: Société de l'histoire de France, 1854: 372-373; VERSORIS, Nicolas. Livre de raison de Maitre Nicolas Versoris, avocat au parlement de Paris (1519-1530). Paris: Société de I'histoire de Paris, 1885: 116; DRIART, Pierre. Chronique parisienne de Pierre Driart, chambrier de Saint-Victor (1522-1535). Paris: Mémoires de la société de l'histoire de Paris et de I'lle de France, vol. 22, 1895: 135)
}

\footnotetext{
${ }^{24}$ Há ediçôes on-line (Google Books, Gallica, Archive.org) de todos esses textos. É bem verdade que a maior parte dos memorialistas franceses não partilha do interesse pelo quotidiano comezinho da vida ordinária: seja porque suas crônicas são politicamente engajadas (estấo a serviço do rei, ou da nobreza, ou de si mesmos nesse contexto aristocrático, tratando exclusivamente de assuntos dessa natureza), seja porque náo faz parte da genealogia intelectual do gênero que entendem estar prolongando (seus arquétipos são as clássicas memórias políticas latinas e as crônicas medievais que lhe constituem a sequência): quer dizer, são crônicas histórico-políticas, não crônicas de costumes. Google Books e Archive.org oferecem todos os volumes das duas séries da Collection des Mémoires relatifs à l'Histoire de France, editadas por Petitot no início do século XIX. Embora editorialmente antigas, elas permitem reconstituir facilmente o contexto contemporâneo dessas narrativas e avaliar a significação discursiva do surgimento do fait divers.

${ }^{25}$ Neste caso, faltaria somente que a narrativa ocupasse ao menos uma página completa, em vez de um único parágrafo: "En l'an 1515, le vendredy vingt deuxiesme de juing, fut décapité un homme à Paris qui avoit tué sa femme, et estoit fiancé à une autre femme, près d'Amiens. Et mena icelle femme au bois de Senac, près Paris, auquel lieu il l'estrangla de sa ceincture, après avoir eu sa compaignie. Et vouloit espouser celle qu'il avoit fiancée, dont il fut accusé et finableraent décapité, comme dit est." (Journal d'un bourgeois de Paris sous le règne de François 1er (1515-1536). Paris: Société de l'histoire de France, 1854: 14).
} 
III.

Pelo tema, nosso texto se situa no rol dos canards criminais ou, mais propriamente, no dos "canards sanglants" ${ }^{26}$ Podemos discutir sua inserção na dinâmica específica que constitui estes últimos, mas, seja como for, temos aí alguns componentes dispersos que definem, em grande parte, a estrutura de um canard em sua generalidade. $\mathrm{O}$ fait divers contém elementos conteurs (ou novelísticos) e informacionais, oscilando entre a narrativa fantástica e o "fato" jornalístico: o nível diegético é recheado de referências tanto bíblicas quanto do noticiário político contemporâneo (Caim e Abel; Salomão e Joabe; Balduíno, Salcedo e o Duque de Anjou; o italiano de Anvers), bem como localizado numa topografia plenamente reconhecível e recuperável: Corpen, Mayence, Berckessel, Alemanha, Treves, Ducado de Luxembourg etc. A hipérbole, dispositivo retórico inerente às histoires admirables típicas do canard - uma das garantias de interesse narrativo negociadas com seu público leitor e/ou ouvinte - está anunciada desde o título: contar-se-á a história verídica do assassino de incriveis 964 almas. Além disso, uma linguagem supostamente intelectualizada, de viés teológico-jurídico-moral em nosso caso, enverniza o contexto, dando-lhe ares de importância erudita, bem como um referente retórico da crônica histórica medievo-renascentista. Esses vetores alimentam as discussōes que conformam o canard enquanto veículo de deleite e informação.

De que maneira esta dinâmica "conteur $\mathrm{X}$ informação" é trabalhada pelo público da época? É possível falar aí de uma pura dinâmica de ficção (decididamente novelística) ou, ao contrário, de uma pura recepção informacional? Não é fácil dizer. Mas não nos enganemos. Em certa medida, a situação do leitor atual é praticamente a mesma do leitor seu contemporâneo: dificilmente se poderia saber se se trata de um hoax ou de uma notícia verídica, de um fato ou de uma invenção. O narrador parece se comprazer nessa imprecisão, anunciando o problema metapoeticamente numa seção importante do texto: tudo isso seria incrivel (em outras palavras, "eu mesmo não acreditaria nisso" - artifício a partir do qual ele mimetiza todos os seus leitores potenciais) se o próprio Cristeman (um

\footnotetext{
${ }^{26} \mathrm{Na}$ feliz expressão de Maurice Lever. Há 109 entradas de canards diretamente relacionados a crimes (duelos, roubos etc.) no repertório de Seguin; os canards sangrentos, mais explícitos na descrição de mortes e suplícios, constituem cerca de 90 entradas e 150 exemplares.
} 
"próprio" que talvez não exista no mundo real) não tivesse anotado, de próprio punho, cada uma das suas mortes num caderno, terrível e bizarra agenda macabra. O serial killer seduz não pelo mistério de uma ação abrupta, imediata, irracional e sem sentido, e sim pela frieza do cálculo infinitesimal: ao que se soma a justeza simbólica do número 1000 , score que selaria, como a obsessão do milésimo gol, sua aposentadoria (tão próxima que sentimos até certa decepção por ele não ter conseguido chegar até lá). ${ }^{27}$

Mas o caderno macabro é, evidentemente, um objeto anódino, funcionando como petição de princípio, sem nada provar (onde está o caderno? quem são os mortos?). Petição de princípio que se responde a si mesma, porém, em diversos níveis do próprio canard. O registro contábil pressupóe uma racionalidade (dirigindo e amplificando a credibilidade do canard) e uma demonstração circunstancial da veracidade dos fatos. Pois a autoridade imputada ao escrito, ao valor do escrito como contraparte da instância oral (operacionalidade dinâmica que, entre outras coisas, constitui o canard enquanto meio de informação), a mera enunciação de existência de um suposto escrito, por mais macabro que seja, por si só já comprovaria por inteiro todas as outras facetas do fait divers, reduzindo a hipérbole "admirable" das inúmeras mortes (dispositivo novelístico) a um conjunto crível, "real" e aceitável (fato jornalístico) pelo leitor-ouvinte. ${ }^{28}$

Desdobramento importante, pois é o mesmo dispositivo que está em operaçẫo junto a "nós", leitores atuais do texto: a racionalidade do cômputo e do ato da sua escrita, do controle quotidiano que ele pressupóe, é um código que atravessa e substitui, mais forte e mais perene, a própria mensagem, irradiando o fait divers

\footnotetext{
27 "How many murders constitute a series? Authorities and sources disagree on that point, demanding anywhere from two to five or six sequential crimes. The Federal Bureau of Investigation (FBI) defines serial murder as 'three or more separate events in three or more separate locations with an emotional cooling-off period between homicides'. Unfortunately, that definition makes no allowance for killers like Jeffrey Dahmer, who murder all their victims in one place, or for those who are caught after only two murders. The National Institute of Justice (NIJ) published a broader definition in 1988, describing serial murder as 'a series of two or more murders, committed as separate events, usually, but not always by one offender acting alone. The crimes may occur over a period of time ranging from hours to years.' Today, while even some FBI agents prefer the NIJ's version, other researchers insist on their own definitions." (NEWTON, Michael; FRENCH, John. Criminal Investigations: Serial Killers. New York: Chelsea House Publishers, 2008: 16).

${ }^{28}$ Em certo sentido, o próprio canard pode ser considerado como um caderno macabro.
} 
com uma possibilidade de verdade que quase se basta a si mesma para garantir o edifício retórico do texto inteiro. O serial killer é, essencialmente, uma persona antissocial com uma obsessão levada ao extremo ${ }^{29}$, etiologia que a imagem dos recém-nascidos, sistematicamente mortos e escorçados a cada ano, flutuando no varal (“dancem, dancem, meus queridos filhos!”, sádicos troféus de pele sob uma enunciação jogralesca e irônica da paternidade ${ }^{30}$ ), ajuda a cristalizar de modo permanente. ${ }^{31}$ Tal etiologia (proveniente da Psiquiatria contemporânea e garantida narrativamente pela suposta existência do caderno macabro), no entanto, não faz mais que realimentar, para nós, o enquadramento do récit, confrontado com seu componente aritmético obviamente absurdo, na escala das coisas possiveis (pois o serial killer age como tal) mas improváveis.

Para o leitor contemporâneo ao canard, porém, privado deste nosso insight etiológico, o caderno macabro é sintoma, não de uma lógica do possivell impossivel (uma vez que o impossível pode acontecer por diversas razóes sobrenaturais ou preternaturais ${ }^{32}$ ), mas sobre-

${ }^{29}$ Grato a Jairo Gama (IMS-UERJ) pela justeza técnica da definição.

30 "In addition to victimology, modus operandi, and signature aspect, the organized/ disorganized classification of serial killers is extremely important in criminal profiling. Organized offenders are hypothesized to kill after undergoing some sort of precipitating stressful event, are of average intelligence, are socially competent, are apt to plan his offenses, use restraints on his victims, take "trophies" or "souvenirs" (items, of little extrinsic value, which belong to the victim and serve to later stimulate the offenders fantasy), bring a weapon to commit the murder and take it with him when he leaves the crime scene." (LABRODE, Rebecca Taylor. "Etiology of the Psychopathic Serial Killer: An Analysis of Antisocial Personality Disorder, Psychopathy, and Serial Killer Personality and Crime Scene Characteristics" in Brief Treatment and Crisis Intervention, Vol. 7, $\mathrm{n}^{\circ}$ 2: 151-160).

${ }^{31}$ Evidentemente, relatos de sádicos hiperbólicos do mesmo naipe já circulavam em território europeu: Gilles de Rais (1405-1440), na França; e Vlad III Tepes (1431-1476), na Valáquia, região dos Cárpatos (conhecido por conta de diversos relatos em russo, romeno e alemão), são os exemplos clássicos - muito embora, controversos. No caso de Vlad III, sua fama de assassino sanguinário foi construída principalmente por seus inimigos, sendo ele herói popular na Romênia: para um dossiê com as fontes ver McNally Raymond; Florescu, Radu. Em Busca de Drácula e outros Vampiros (1992), São Paulo: Mercuryo, 1995. No caso de Gilles de Rais, companheiro de Joana D’Arc posteriormente condenado por uma série de crimes (que incluíam infanticídios, sodomia, invocaçóes demoníacas), foi reabilitado por diversos autores modernos. Ver Bossard, Eugène. Gilles de Rais, Maréchal de France, Paris: Honoré Champion, 1885; Bataille, Georges. "Le Procès de Gilles de Rais" in Bataille, Georges. Euvres complètes, Tome X. Paris: Gallimard, 1987: 271-571; e Parsons, Ben. "Sympathy for the Devil: Gilles de Rais and His Modern Apologists" in Fifteenth Century Studies, Vol. 37, 2012: 113-137. ${ }_{32}$ Trata-se, pois, de uma longa discussão, que envolve uma sistemática fenome- 
tudo de uma lógica do provável. Para a repetição crível de um fenômeno não diretamente visto - pois, apesar disso, bandidos existem, bandidos matam pessoas em emboscadas na estrada, sobretudo se agem sem punição "pelo espaço de treze anos" ${ }^{33}$ - bastaria a existência (suposta) de um registro das mãos dos próprio psicopata: eis tudo o que é necessário para torná-lo um fato inequívoco. ${ }^{34}$ Por-

nológica na qual o reino das coisas não se restringe unicamente ao mundo natural (com leis imutáveis e constantes), mas que também envolve o sobrenatural (divino) e o preternatural (a hachura que intersecciona os dois anteriores e que corresponde à ação de seres e eventos extraordinários, como demônios, portentos e prodígios) e que pode ser modificado segundo certas circunstâncias: "From the point of view of causal analysis, the preternatural posed special problems, largely because it was a negative category - and a negative category, furthermore, whose limits were defined in practical terms by a pair of unstable criteria both of which depended on the experience and knowledge of the viewer: that which was infrequently experienced or that at which the ignorant wondered. As a result, the preternatural consisted of a stratigraphy of heterogeneous phenomena, built up in layers from several different traditions with no internal coherence except their awkward relationship to scientia in the Aristotelian sense. These phenomena might include (depending on the author in question): conjuring tricks; natural substances (domestic and, especially, exotic) endowed with occult properties, as well as other staples of the ancient paradoxographical tradition; necromancy and other forms of demonic intervention; and chance or accidental phenomena as defined by Aristotle himself. Although thirteenth-and fourteenth-century philosophers might agree on the importance of supplying natural causes for such effects, they differed significantly as to the specific sorts of causes involved, particularly once the influx of Arabic philosophical writing in the twelfth century had vastly expanded the very limited repertory of causal mechanisms previously available to Latin writers" (Daston, Lorraine; Park, Katharine. Wonders and the Order of Nature (1150-1750), New York: Zone Books, 1998: 126). Ver também Daston, Lorraine. "Marvelous Facts and Miraculous Evidence in Early Modern Europe" in Critical Inquiry, Vol. 18 n 1, 1991: 93-124.

${ }^{33}$ Não é à toa que o caso Cristeman propriamente dito é precedido, e ele próprio recheado, de referências a sistemas quantitativos: "Crueldades de malfeitores existem em vários livros e tratados (...)"; "Muitos assassinos foram executados por esta razão (...)"; "As Escrituras entretanto, tanto do Velho Testamento quanto as histórias profanas lhe fazem fé (...)"; "provisöes de vinho e de carnes frescas e salgadas para durar um ano (...)"; "armas de todos os tipos e em grande número"; "todo tipo de mercadoria, roubadas de alemáes e de outros, em tal quantidade que poderiam abastecer uma feira (...)"; "muitos estimaram chegar a valer mais que de setenta mil florins de ouro da Alemanha" etc., até finalmente chegarmos à frase capital "sua meta era matar até chegar ao número de mil pessoas". O número, neste caso, é uma máquina de credibilidade.

${ }^{34}$ A demonologia renascentista utiliza esse mecanismo. É óbvio que, de seu ponto de vista, certas coisas impossíveis são, de fato, impossíveis; mas certas coisas impossíveis, se inseridos aí determinados elementos disruptivos, tornam-se, senão totalmente possiveis, ao menos prováveis. Eis a suposição que importa para o demonólogo. É por esse motivo que, embora voar pelos ares numa vassoura seja um "fato" alegado mas obviamente jamais aferido em flagrante por nenhuma instân- 
tanto, sem o movimento crítico-epistemológico contrário de uma verdadeira auctoritas para contrabalançá-lo - provido, por exemplo, por um teólogo ou por um jurista (daí, aliás, a importância do verniz intelectual de legitimação na retórica do nosso canard) -, o fait divers tem uma credibilidade narrativa inercial veloz e difícil de ser contida. Em outras palavras, esse "dispositivo do provável", em certa medida, é o mesmo do rumor: a noção científica e empírica de veracidade não se aplica aqui, pois o rumor é uma deliberação coletiva. ${ }^{35}$ Neste sentido, esse dispositivo acaba reforçando uma possibilidade mágica do mundo concreto - a de se reinventar a partir de uma pequena fresta do imaginário e do condicional, o que permite modelar inumeráveis mundos possíveis onde o incrível Cristeman poderia efetivamente estar e agir. Um contexto apocalíptico, milenarista ou escatológico, por exemplo, no qual as misteriosas interfaces do comportamento divino (sempre em jogo no nosso fait divers) incitariam a imaginação e o engendramento de quimeras incompreensíveis, é o tipo de contexto que permitiria essa modelagem contrafactual contrabandeada para o real (seja lá o que for o real). ${ }^{36}$

cia penal conhecida (inquisitorial ou laica), ele poderá sempre enviar à masmorra um acusado desse tipo de proeza: é a soma das narrativas (neste caso, eruditas e/ou populares) que afirmam o fenômeno preternatural que torna sua existência real. "Linterrogation sur le statut des opérations diaboliques, réalité ou illusion, sinsère en effet sans doute dans une problématique plus générale qui touche à l'évolution des concepts de fiction, de croyance et de probabilité. La seconde moitié du seizième siècle est l'époque où commence à se faire jour une pensée autonome de la fiction poétique comme domaine de l'imaginaire, où simpose la notion de croyance (comme s'appliquant à des objets inexistants), et où évolue le concept de probabilité. Le débat, central pour la démonologie, porte encore pendant la Renaissance essentiellement sur le statut de l'opinion sur laquelle se fonde le probable : recouvre-t-il ce qui est cru par le vulgaire ou ce qui est attesté par des autorités? Cependant, la notion de probabilité commence justement à se détacher de l'opinion, tandis que simposera dans la deuxième moitié du dix-septième siècle l'objectivation du probable, c'est-à-dire l'idée qu'il se fonde sur la fréquence statistique" (Lavocat, Françoise. "L'Arcadie diabolique" in Lavocat, Françoise; Kapitaniak, Pierre; Marianne Closson. Fictions du diable, Genève: Droz, 2007: 59).

${ }^{35}$ Kapferer, Jean-Noël. Rumeurs. Le plus vieux média du monde. Paris: Seuil, 2009: 17. Para a discussão, ver SHIBUTANI, Tamotsu. Improvised News. A Sociological Study of Rumor. Indianapolis: The Bobbs-Merril Company, 1966; PAILLARD, Bernard. "La rumeur, ou la preuve ordinaire" in Communications, Vol. 84, 2009: 119-135; RENARD, Jean-Bruno, Rumeurs et légendes urbaines, Paris: PUF, 20073; CAMPION-VINCENT, Véronique. La Société parano. Théories du complot, menaces et incertitudes. Paris: Payot, 2007.

${ }^{36}$ No momento atual, diversos tipos de fenômenos "preternaturais laicos" (os da esfera midiática, por exemplo), sem necessariamente se estabelecerem em con- 
Sem contar, claro, que esses componentes, às vezes distintos às vezes simbióticos, fornecem uma óbvia musculatura midiática e icônica que certamente concorreu para a perpetuação e a disseminação editorial do nosso canard. ${ }^{37}$

Além disso, temos outra negociação, ainda mais sutil, indireta, entre o extraordinário (definindo o espaço conteur-novelístico do canard) e o banal (que define o espaço ordinário e concreto do leitor-ouvinte). Pois o canard rapidamente se desembaraça do incrível, do admirable número de vítimas de Cristeman Gempertingua para se concentrar na aventura singular da "mulher": anônima, como convém à "mulher", essa vítima infeliz porém bela (beleza que lhe salvou a vida mas que lhe custou a liberdade, verdadeira fábula da opressão genérica), sequestrada e mantida em cativeiro durante sete anos, é uma versão renascentista das Nataschas Kampusch, das Jaycees Dugard, das Michelles Knight, das Elisabethes Fritzl (em outras palavras, um fait divers em si). ${ }^{38}$ Genitora "que se

textos de ordem escatológica, foram contrabandeados do "mundo provável" para o "nosso" mundo real. Podemos ver a fabricação desse tipo de fenômeno, por exemplo, na progressiva naturalização do Slender Man: uma criatura sinistramente neutra, esguia, tentacular e sem rosto, vestida como um executivo de Wall Street, criada por Erik Knudsen para um fórum na web em 2009, corporificada a partir de diversas contribuiçôes narrativas e artísticas e que existe hoje como lenda urbana. Um fait divers recente (31 de maio de 2014) relata as maquinaçóes de duas pré-adolescentes americanas, Morgan Geyser e Anissa Weier, de 12 anos, moradoras de Waukesha (Wisconsin), que convidaram uma amiga para um passeio, lhe desferiram 19 facadas pelo corpo e a deixaram agonizante em um bosque. Seu propósito: cometer um assassinato para tornarem-se "representantes da criatura, provando de fato a sua existência” (Cf. Gusmão, Gustavo. "Jovens tentam assassinar colega para 'agradar' Slender Man, lenda urbana surgida na web” In: Info Online. Disponível em: http://info.abril.com.br/noticias/ internet/2014/06/jovens-tentam-assassinar-colega-para-agradar-o-slender-man. shtml. Acesso em 03/06/2014).

${ }^{37}$ É pouco provável que se saiba algo a respeito da circulação concreta deste fait divers a fim de se poder quantificar seu sucesso público, mas sua existência no acervo da BNF talvez seja aí um índice importante. Em todo caso, nos EUA de hoje, o serial killer é intensamente explorado pelos veículos de comunicação, criando uma verdadeira economia cultural, a murderabilia: "The celebrity culture around serial killers has developed so far that one can now purchase the nail clippings and hair of some killers, as if they were religious icons." (SCHMID, David. Natural born celebrities: serial killers in American culture. Chicago: The University of Chicago Press, 2005: 3).

${ }^{38} \mathrm{O}$ relato autobiográfico de Kampusch (sequestrada aos dez anos em Strasshof an der Nordbahn, perto de Viena, pelo técnico em comunicaçôes Wolfgang Priklopil e mantida em cativeiro de 1998 a 2006) foi publicado em 2010. Nele, Kampusch transfigura magistralmente a idealização feminina da infância em perfeito realismo, coroado com a aplicação do dado científico: "Na época, eu ti- 
arrependia continuamente dos pecados que cometera (sic)", zelosa de um juramento completamente absurdo diante das circunstâncias, que precisa ser prévia e excepcionalmente absolvida de perjúrio pelos magistrados (instâncias essencialmente masculinas) interessados em sua história "desde que", é claro, "isso não represente a perdição de sua alma”. E como saber se o que ela entende por salvar sua própria alma obedece aos mesmos critérios? É como "mulher", com artifícios típicos da tromperie feminina (o uso de "belas frases"; o cafuné sórdido que adormece o troglodita em seu colo no leito conjugal) que ela vira o jogo; é como estereótipo que ela segue para enganar Cristeman e entregá-lo a seus algozes. E, finalmente, é como "puta desleal", titulação dada pelo monstro que aqui se transmuta subitamente em pobre marido enganado, que ela desaparece por completo da cena do canard: depois de cumprir seu papel (um papel secundário, portanto, apesar de fundamental) nos insondáveis propósitos divinos, diversas vezes invocado pelo narrador como aspecto moralizante prioritário do fait divers. Nada mais ordinário que uma mulher em sua ordinária condição de "mulher".

Sem nos darmos conta, o texto, apesar das intençóes declaradas e aparentemente imediatas do narrador (falar a respeito do maior serial killer de todos os tempos), é na verdade a história de uma vingança divina e feminina, onde esta se traveste daquela. É graças à mais banal das caracterizaçoóes genéricas, a mulher-trompeuse, a mulher-infiel, a mulher-traidora, que a narrativa consegue ser resolvida - tanto no nível subtextual quanto no teológico-jurídico-moral. É através da traição da mulher que os planos divino e humano se encontram novamente estáveis, e as justiças, divina e humana, tấo conclamadas pelo texto, podem finalmente ser cumpridas: mas supliciado na roda, alimentado e hidratado para sofrer

nha uma imagem clara das vitimas de sequestro: meninas louras, pequenas e muito magras, quase transparentes, que flutuavam pelo mundo de modo angelical e indefeso. Eu as imaginava como criaturas com cabelos tão sedosos que era preciso tocá-los. Sua beleza paralisava homens doentes, transformando-os em bandidos violentos para mantê-las por perto. Eu, ao contrário, tinha cabelos escuros e me sentia gorda e normal. E na manhã do sequestro, mais do que nunca, eu me sentia assim. Não me adequava à imagem que fizera de uma menina sequestrada. Hoje acho que essa imagem era falsa. Crianças pouco atraentes, com baixa autoestima, é que são escolhidas como vitimas de sequestradores. A beleza não é um fator quando se trata de violência sexual. Pesquisas mostram que deficientes fisicos e mentais, assim como crianças sem ligaçōes familiares correm maior risco de se tornar vitimas de um sequestrador." (KAMPUSCH, Natascha. 3096 dias. Campinas: Verus Editora, 2010³: 67). 
o máximo possível, sem braços nem pernas, Cristeman Gempertingua não deixará de surpreender - durará nove dias. ${ }^{39}$ Assim seja.

Rafael Marcelo Viegas é Bacharel em Filosofia (1997, IFCH-UERJ), Mestre (2001) e Doutor (2008) em Saúde Coletiva pelo Instituto de Medicina Social (IMS) da UERJ, Doutor em Letras Neolatinas pela Faculdade de Letras da UFRJ (2014). E-mail: <rafaelmviegas@gmail.com>.

39 "Un édit de 1534 réserva la roue aux parricides et aux voleurs à main armée; mais Henri II étendit la punition aux assassins : elle devint dès lors très populaire, voire banale. (...) En réalité, les juges autorisaient dans la majorité des cas, l'étranglement du criminel [o chamado retentum] avant le bris de ses membres. (...) Quand les juges n'avaient pas prévu de 'retentum' et que le voleur faisait preuve d'une grande résistance physique, il fallait solliciter l'autorisation expresse de l'étrangler. Le nommé Desmoulins, âgé de dix-sept à dix-huit ans "a été rompu mardi (18 décembre 1742), à midi. C'était un garçon si robuste et même très résolu, qu'il est resté vingtdeux heures vif sur la roue. On a relayé des confesseurs pendant la nuit, d'autant que la place sur un échafaud est un peu froide. Et ledit Sieur Desmoulins a bu plusieurs fois de l'eau et a beaucoup souffert. Enfin, voyant qu'il ne voulait pas mourir, et que le service était long, $M$. le lieutenant criminel a envoyé demander à messieurs de La Tournelle la permission de le faire étrangler»" (VILLENEUVE, Roland. Le musée des supplices. Paris: Ed. Azur, 1968: 114 e 115). 